\title{
Application of Geo-informatics Technology to Access the Surface Temperature Using LANDSAT 8 OLI/TIRS Satellite Data: A Case Study in Ampara District in Sri Lanka
}

\author{
Zahir, I. L. M. * \\ Department of Geography, South Eastern university of Sri Lanka, Oluvil, Sri Lanka \\ zahirilm_gis@seu.ac.lk \\ * Correspondence: zahirilm_gis@seu.ac.lk; Tel.: (+94 774828005, +94 768409889)
}

\begin{abstract}
Land Surface Temperature is a one of the key variable of Global climate changes and model which estimate radiating budget in heat balance as control of climate model. It is a major influenced factor by the ability of the surface emissivity. In this study, were used Landsat 8 satellite image that have Operational Land Imager and Thermal Infrared Sensor to calculate Land Surface Temperature through geospatial technology over Ampara district, Sri Lanka. The Land Surface Temperature was estimated with respect to Land Surface Emissivity and Normalized Difference Vegetation Index values determined from the Red and Near Infrared channels. Land Surface Emissivity was processed directly by the thermal Infrared bands. Pixels based calculation were used to effort at LANDSAT 8 images that thermal Band 10 various dates in this study. The results were achievable to compute Normalized Difference Vegetation Index, Land Surface Emissivity, and Land Surface Temperature with applicable manner to compare with land use/ land cover data. It determines and predicts the changes of surface temperature to favorable to decision making process for the society. Study area faces seasonal drought in Sri Lanka, the prediction method that how land can be efficiently used with the present condition. Therefore, the Land Surface Temperature estimation can prove whether new irrigation systems for agricultural activities or can transformed source of energy into useful form that introducing solar hubs for energy production in future.
\end{abstract}

Keywords: land surface temperature; operational land imager; thermal infrared sensor; normalized difference vegetation Index; geospatial technology

\section{Introduction}

Land surface temperature (LST) is the radioactive temperature over the land that how hot the "surface" of the Earth would feel to the touch in a particular location which is plays an importance role in the physics of land surface as it is involved in the processes in the energy and water exchange over the atmosphere. LST is useful of scientific community, namely for those dealing with not only climate change studies but key input metrological and climate modeling such as urban land use, geospatial and biophysical. Land surface emissivity (LSE), an essential parameter LST retrieval from a satellite's point of view, the "surface" is whatever it sees when it looks through the atmosphere to the ground. Thus, LST is not the same as the air temperature that is included in the daily weather 
condition. It is also a fundamental aspect of climate and biology, affecting organisms and ecosystems from local to global scales.

LST measures the emission of thermal radiance from the land surface where the incoming solar energy interacts with heats the earth surface of the canopy in vegetated areas. This quality makes LST a good indicator of energy partitioning at the LST boundary and sensitive to changing surface conditions. Urbanization in local and global scale are significantly reformed the landscape, the combining the results of all surface temperature interactions and energy fluxes between the atmosphere and the ground [8]. It has key climatic effects at right angles at all scales by the real-time transformation of natural land cover in the earth surface. Identification and characterization of Urban Heat Island (UHI) is typically based on LST that varies spatially, due to the non-homogeneity of land surface cover and other atmospheric factors [4].

Typically, Land use/ Land cover classes can be provided to precise information by Ground survey methods; however, it would be time-consuming, difficulties and expensive manner. The remote sensing technology is preferred to alternative solution to extracting for land resources, climatic scenarios and other physical features from earth surface. The Landsat and Spot satellite images are appropriated for vegetation mapping of surface are at medium spatial resolution in regional and local scale. LANDSAT 8 image has two sensors, that Operational Land Imager (OLI) and the Thermal Infrared Sensor (TIRS). OLI sensor is collecting data at a $30 \mathrm{~m}$ spatial resolution with eight bands, the wavelength visible ranges are near-infrared and the shortwave infrared regions of the electromagnetic spectrum, and an additional panchromatic band of $15 \mathrm{~m}$ spatial resolution. TIRS the TIR radiance at a spatial resolution of $100 \mathrm{~m}$ using two bands located in the atmospheric window between 10 and $12 \mu \mathrm{m}$ [4 and 10].

\section{Materials and Methods}

\subsection{Study Area}

Ampara district is a part of district of Eastern Province in Sri Lanka. The district consists an area of 4494 square kilometers. The district lies approximately between $6^{0} 28^{\prime} 59^{\prime \prime}-7046^{\prime} 9^{\prime \prime} \mathrm{N}$ and $80^{\circ} 58^{\prime}$ $59^{\prime \prime}-81^{0} 52^{\prime} 40^{\prime \prime} \mathrm{E}$ (Lat/Long respectively) (fig. 1). It has consisted tow climatic zones as dry and intermediate. 45 percent of the total land is enclosed by forests in the district. Because of the higher altitude of the western parts compared to the eastern parts of the district, the general feature is uniform temperature with minor fluctuations. The mean annual temperature is high registering a record falling between $25^{\circ} \mathrm{C}$ and $27^{\circ} \mathrm{C}$. This change seasonally noticeable to a maximum of $27^{\circ} \mathrm{C}$ during March - April when sunshine is the highest. The lowest temperature is during November December - January when temperature throughout the island is relatively low and the impact of the Northeast monsoon is present. At this time, the monthly mean temperature is $26^{\circ} \mathrm{C}$ and during the months of December and January it falls to $25^{\circ} \mathrm{C}$. In May - June, however, the temperature is higher as in March and April, during which time the monthly mean is about $27^{\circ} \mathrm{C}$. The main reason for such high temperature is the shielding of the winds from the west by the Central Mountains of the country. Year - round high temperature in the district is accompanied with low rainfall. Its average annual rainfall is $1000 \mathrm{~mm}-2000 \mathrm{~mm}$, which is registered during two short seasons in a year. The higher rainfall is recorded during the Maha season, when the northeast monsoon operates and between 500 $\mathrm{mm}$ and $1000 \mathrm{~mm}$ are received. More than 50 percent of the rain received in the district comes from the northeast monsoon. The southwest monsoon, during May - September is not too fruitful of rain with only $250 \mathrm{~mm}-500 \mathrm{~mm}$ which is only 10 percent of the district's total rainfall. 


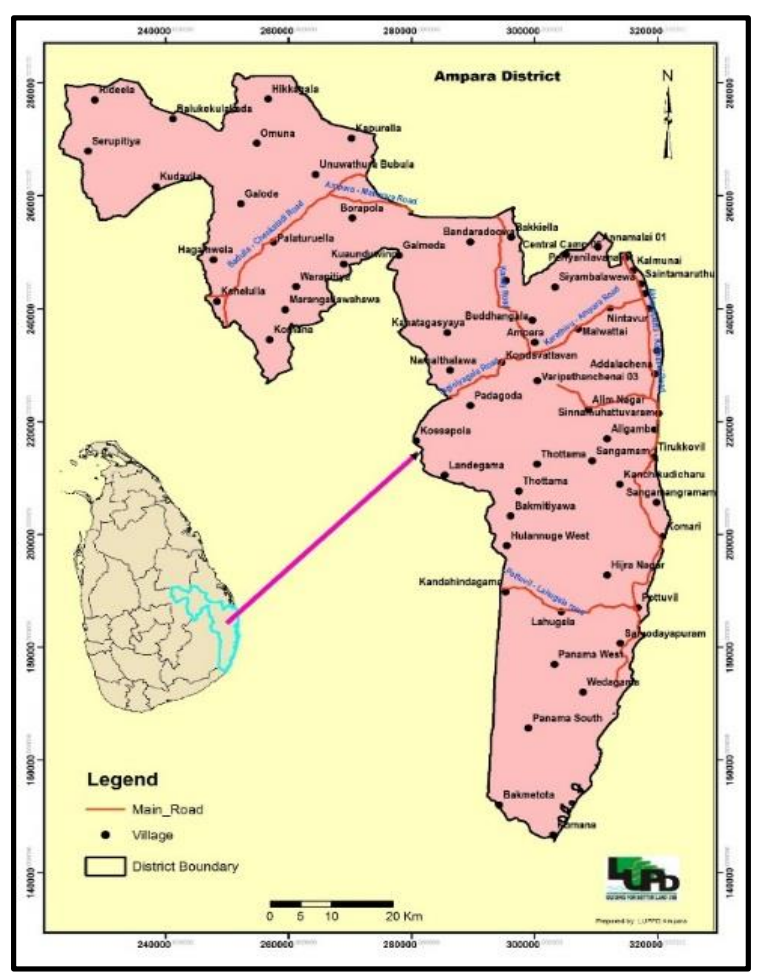

Fig. 1: Study Area

\subsection{Materials}

In this study, the multispectral Landsat 8 carries a two sensor payload, OLI/TIRS Level 1 and Level 2 images were used entire area of Ampara district date were acquired a path/row 140/55 and 141/55 same periods from United State Geological Survey (USGS) website: http://earthexplorer.usgs.gov/ (see fig. 2). The OLI and TIRS spectral bands could broadly be compared to the Landsat 7 Enhanced Thematic Mapper Plus (ETM+) bands. When compare to the ETM+, the OLI has two additional reflected wavelength bands that a new shorter wavelength blue band $(0.34-0.45 \mu \mathrm{m})$ intended for improve sensitively for chlorophyll and other suspended materials in coastal water and for retrieving atmospheric aerosol properties and a new shortwave infrared band $(1.36-1.39 \mu \mathrm{m})$ for cirrus cloud detection. The other OLI bands are spectrally narrower in the most cases than the corresponding ETM+ bands. The TIRS sense emitted radiance in two $100 \mathrm{~m}$ thermal infrared bands which compared to the high and low gain single thermal infrared $60 \mathrm{~m}$ ETM+ band. The reduced TIRS spatial resolution is not optimal but necessitated by engineering cost restrictions. However, the tow thermal TIRS bands enable thermal wavelength atmospheric correction and more reliable retrieval of surface temperature and emissivity.

The study area was preferred includes built-up area, water bodies, bare soil, rockiness and vegetation cover. The nearest neighbor method was employed in resemble techniques. Thus, all the data were re-projected to a Universal Transverse Mercator (UTM) project coordinate system, datum WGS84, zone 44. 


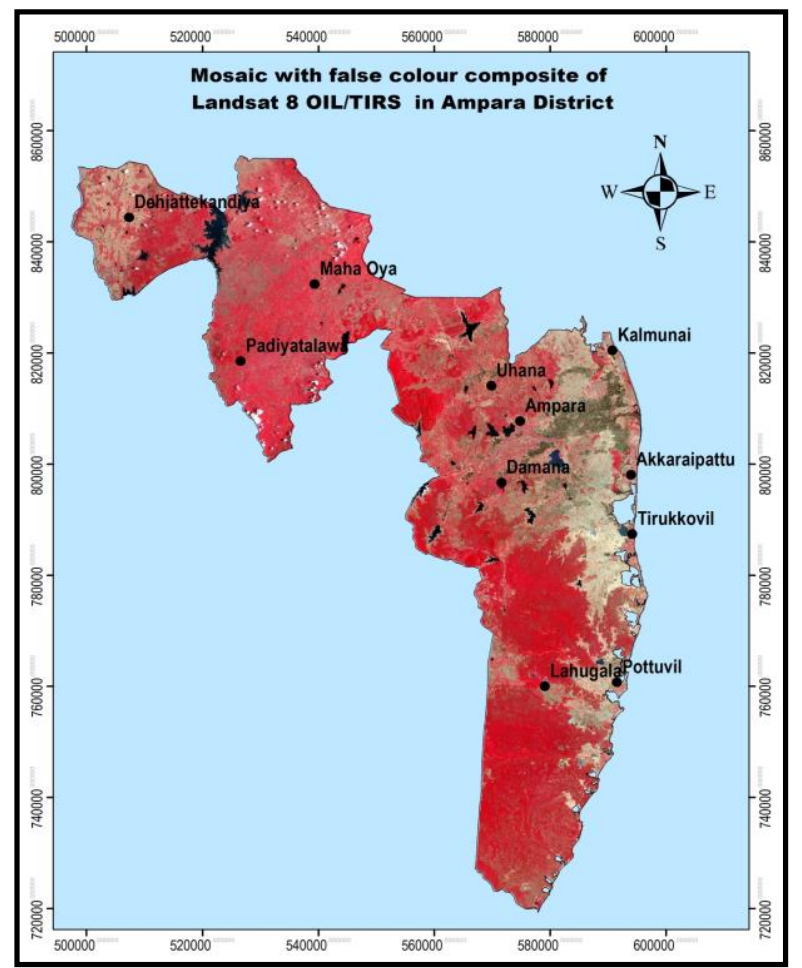

Fig. 2: False Color Composition Landsat 8 OLI/TIRS

LST was evaluated by to the proposed approach that to process Landsat 8 satellite images. The satellite image products were corrected by geometrically. The first step of the proposed work was converted the Digital Number (DN) values to Top of the Atmosphere (TOA) of band10 to atsensor spectral radiance using the equation (1) [5, 7 and 10].

$$
\mathrm{L}_{\lambda} \frac{(\text { Lmax }- \text { Lmin }) * Q c a l}{(Q \operatorname{calmax}-Q \operatorname{calmin})}+=\mathrm{Lmin}_{\mathrm{m}}-\mathrm{O}_{\mathrm{i}}
$$

where, (see table 1)

Lmax is the maximum radiance $\left(\mathrm{Wm}^{-2} \mathrm{sr}^{-1} \mu \mathrm{m}^{-1}\right)$

Lmin is the minimum radiance $\left(\mathrm{Wm}^{-2} \mathrm{sr}^{-1} \mu \mathrm{m}^{-1}\right)$

Qcal is the DN value of pixel

Qalmax is the maximum DN value of pixels

Qcalmin is the minimum DN value of pixels

Oi is the correction value for band 10

Therefore, TOA reflectance with a correction for the sun angle as following (the equation 2):

$$
\mathrm{O}_{\mathrm{i}}=\frac{\mathrm{L} \lambda}{\operatorname{Cos}(\theta S Z)} \text { or } \quad \frac{\mathrm{L} \lambda}{\operatorname{Sin}(\theta S E)}
$$

where,

( $\mathrm{O}_{\mathrm{i}}$ was obtained by correction for sun angle $=$ TOA reflectance $/$ Cos (Local solar zenith angle) or TOA reflectance/ Sin (Sun elevation) for more accurate reflectance calculator, per pixel solar angle could be used instead of the sense centre solar angle, but pixel solar zenith angle is not currently provided with the Landsat products) 
Table 1: Metadata of the Landsat 8 Image

\begin{tabular}{|c|c|l|}
\hline Variable & Value & \multicolumn{1}{|c|}{ Descriptions } \\
\hline $\mathrm{K}_{1}$ & 774.8853 & Thermal constants, Band 10 \\
$\mathrm{K}_{2}$ & 1321.0789 & \\
\hline $\mathrm{L}_{\min }$ & 22.00180 & $\begin{array}{l}\text { Minimum and maximum } \\
\text { value of radiance, Band 10 }\end{array}$ \\
\hline Lmax $_{\text {malmin }}$ & 0.10033 & $\begin{array}{l}\text { Minimum and maximum } \\
\text { value of quantize calibration, } \\
\text { Band 10 }\end{array}$ \\
\hline $\mathrm{Q}_{\text {calmax }}$ & 65535 & Correction value, Band 10 \\
\hline $\mathrm{Q}_{\mathrm{i}}$ & 0.29 &
\end{tabular}

(Source: Metadata file of Landsat 8 OLI/TIRS)

After converting DN values to at- sensor spectral radiance, the TIRS band data was converted to brightness temperature (BT) using the thermal constants given in metadata file and the equation (3) [7]:

$$
\mathrm{BT}=\frac{K 2}{\operatorname{In}\left[\left(\frac{K 1}{L \lambda}\right)+1\right]}-273.15
$$

where,

$$
\begin{aligned}
& \mathrm{BT}=\text { Top of atmosphere brightness temperature }\left({ }^{\circ} \mathrm{C}\right) \\
& \mathrm{L}_{\lambda}=\text { TOA spectral radiance }\left(\text { Watts } /\left(\mathrm{m}^{2}{ }^{*} \mathrm{sr}^{*} \mu \mathrm{m}\right)\right) \\
& \mathrm{K}_{1}=\mathrm{K}_{1} \text { Constant Band (No.) } \\
& \mathrm{K}_{2}=\mathrm{K}_{2} \text { Constant Band (No.) }
\end{aligned}
$$

$K_{1}$ and $K_{2}$ values can be identified by the thermal coefficients of TIR band 10 in the metadata file allied with the satellite image. In this process, the temperature results will be estimated in Celsius, it is needed to revise by adding absolute zero which is approximately equal to -273.15 . Since the atmosphere in our research area is comparatively dry and therefore, the range of water vapor values is relatively small, the atmospheric effect is not taken into consideration in retrieving the LST [3].

Bands 4 and 5 were used to determine normalize difference vegetation index (NDVI) which is important to pinpoint different land cover types of the study area. It is a good indication of vegetation bio-shield mass estimation and vegetation health [6]. NDVI ranges between -1.0 to +1.0 ; it can be calculated on per-pixel basis as the normalized difference between the red band $(0.64-0.67 \mu \mathrm{m})$ and near infrared band $(0.85-0.88 \mu \mathrm{m})$ of the images using the equation (4) [3].

$$
\mathrm{NDVI}=\frac{(N I R-R e d)}{(N I R+R e d)}
$$

where,

$\mathrm{RED}=\mathrm{DN}$ values from the RED band 
NIR= DN values from Near-Infrared band

NIR is the near infrared band value of a pixel and RED is the red band value of the same pixel. Calculation of NDVI is necessary to further calculate Proportional Vegetation $(\mathrm{Pv})$ and emissivity $(\varepsilon)$.

Thus, to calculate Pv from NDVI values obtained in formula 4. It gives the estimation of area under each land cover type. The vegetation and bare soil proportions are acquired from the NDVI of pure pixels. Values of NDVIv $=0.5$ and NDVIs $=0.2$ were proposed to apply in global conditions while the value for vegetated surfaces (NDVIv $=0.5$ ) may be too low in some cases, for higher resolution data over agricultural sites, NDVIv can reach 0.8 or 0.9 [10]. Pv was calculated using the equation (5).

$$
\mathrm{PV}=\left[\frac{\text { NDVI-NDVImin }}{\text { NDVImax+NDVImin }}\right]^{2}
$$

where,

$$
\begin{aligned}
& \text { PV }=\text { Proportion of Vegetation } \\
& \text { NDVI = DN values from NDVI Image } \\
& \text { NDVI min = Minimum DN values from NDVI Image } \\
& \text { NDVI max = Maximum DN values from NDVI Image }
\end{aligned}
$$

Calculation of LSE is required to estimate LST since, LSE is a proportionality factor that scales the black body radiance (Plank's law) to measure emitted radiance and it is the ability of transmitting thermal energy across the surface into the atmosphere [9]. At the pixel scale, natural surfaces are heterogeneous in terms of variation in LSE. In addition, the LSE is largely dependent on the surface roughness, nature of vegetation cover etc [2]. LSE is the average emissivity of an element of the surface of the earth calculated from NDVI values using the equation (6).

$$
\mathrm{E}=0.004^{*} \mathrm{Pv}+0.986
$$

where,

$$
\begin{aligned}
& \mathrm{E}=\mathrm{LSE} \\
& \mathrm{P}_{\mathrm{V}}=\text { Proportion of Vegetation }
\end{aligned}
$$

The LST is the radiative temperature which calculated using Top of atmosphere brightness temperature, wavelength of emitted radiance, LSE using equation (7) [1].

$$
\mathrm{LST}=\left(\frac{B T}{1}\right)+W *\left(\frac{B T}{14380}\right) * \operatorname{In}(E)
$$

where,

$$
\begin{aligned}
& \mathrm{BT}=\text { TOA brightness temperature }\left({ }^{\circ} \mathrm{C}\right) \\
& \mathrm{W}=\text { Wavelength of emitted radiance } \\
& \mathrm{E}=\mathrm{LSE}
\end{aligned}
$$


Table 2: Wavelength of thermal bands in Landsat 8

\begin{tabular}{|c|c|}
\hline \multicolumn{1}{|c|}{ Bands } & Wavelength $(\boldsymbol{\mu m})$ \\
\hline 10 & 10.8 \\
\hline 11 & 12 \\
\hline
\end{tabular}

(Source: Metadata file of Landsat 8 OLI/TIRS)

The LST is emitted using land use/ land cover classification. Therefore, it is a necessary step in order to calculate surface emissivity. Land use/ land cover were classified as seven classes (Built-up, Paddy land, Vegetation, Sandy area, Water bodies, Bare Land and Cloud cover).

\section{Results and Discussion}

The LSE is derived by ranges from 9.987 to 0.989 in the study area. High elevated region in the district had more vegetation cover even LSE is high. Higher rate of LSE is found in western, Northwest and South-West regions whereas lower proportion is found in the eastern part of the study area without settlement of the study areas (see fig. 3).

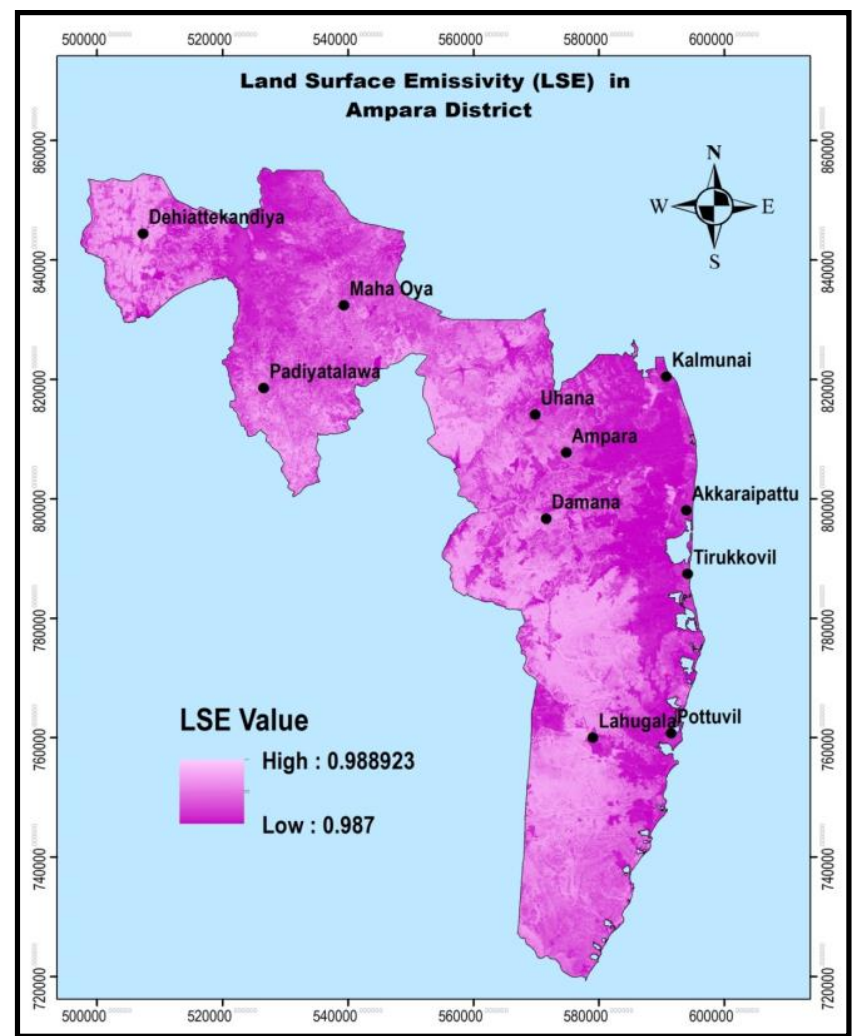

Fig. 3: Range of Land Surface Emissivity in Ampara District

(Source: Computed by Author form Landsat 8 OLI/TIRS Data Level 2)

NDVI is an isolate tool to specify different land cover/ land use types of the study area. It is a good indication of vegetation bio-shield mass estimation and healthy of vegetation proportion. NDVI ranges between -1.0 to +1.0 ; it was estimated ranges from -0.56 to 0.91 in the study area that on per- 
pixel basis as the normalized difference between the red band $(0.64-0.67 \mu \mathrm{m})$ and near infrared band $(0.85-0.88 \mu \mathrm{m})$ of the images using the formula. Hence, water bodies are lower region and dense vegetation cover is higher value. Western part of area vegetation is higher also NDVI value as well in the study area.

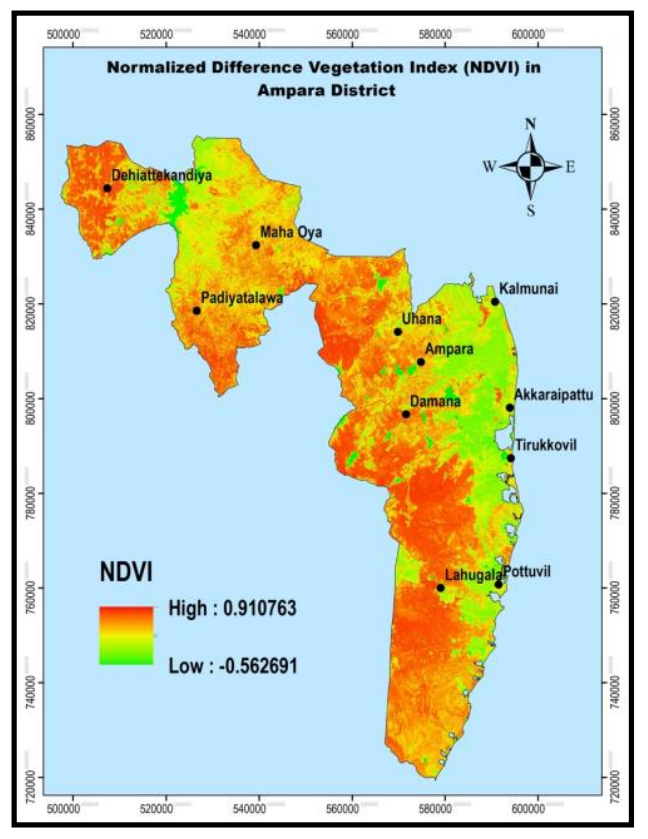

(a)

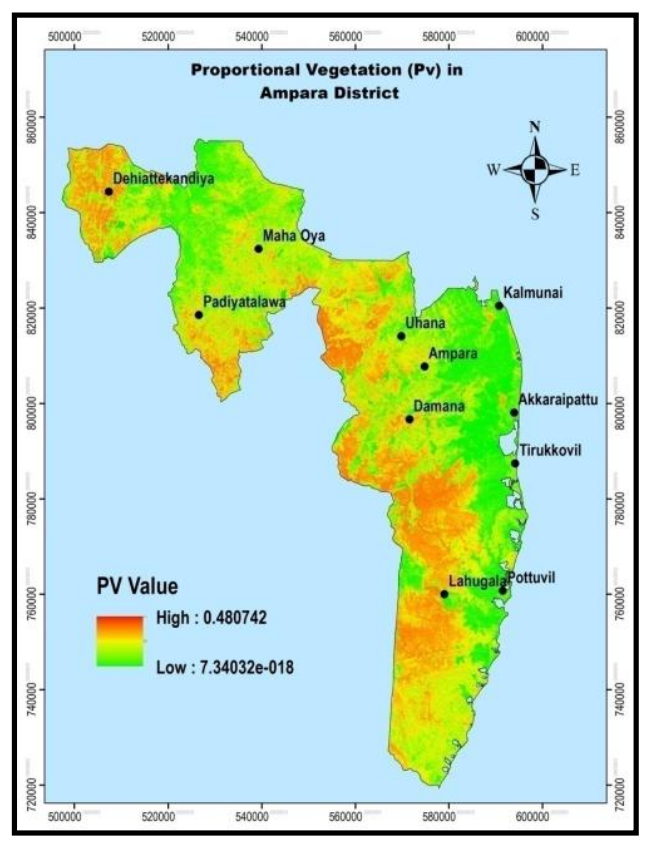

(b)

Fig. 4: (a) Range of NDVI value and (b) in Range of PV value in Ampara District (Source: Computed by Author form Landsat 8 OLI/TIRS Data Level 2)

In this study, Spectral Angle Mapping (SAM) algorithm is used for land use classification which is physically based spectral method that an n-D angle to match pixel to reference spectra. Hence, LST was calculated using NDVI for the estimation of LSE for each class (see table 3). Then, the values were reclassified to determine LST to particular land use class.

Table 3: Land Use Classes and its Emissivity Value

\begin{tabular}{|l|r|}
\hline \multicolumn{1}{|c|}{ Land Use Classes } & Emissivity Value \\
\hline Built-up & 0.9876 \\
\hline Paddy Land & 0.9870 \\
\hline Vegetation & 0.9885 \\
\hline Water bodies & 0.9871 \\
\hline Bare Land & 9.9884 \\
\hline Cloud & 0.0 \\
\hline
\end{tabular}

DN value to TOA: The DN values of thermal infrared sensor were converted into TOA to atsensor for spectral radiance. Hence, the higher values were retrieved from bare land areas and lower values in water pixels. 


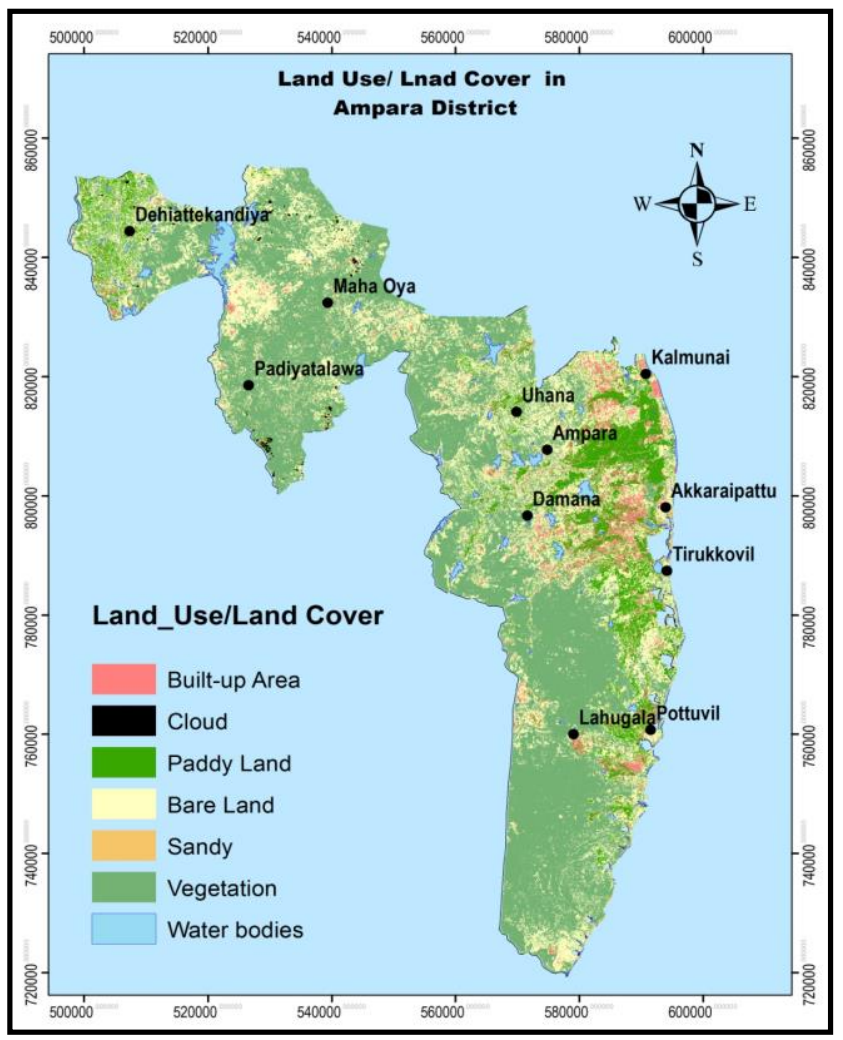

Fig. 6: Classification of Land Use/ Land Cover in Ampara District (Source: Computed by Author form Landsat 8 OLI/TIRS Data Level 1)

BT: After converting DN values to at-sensor spectral radiance, the TIRS band data was converted to BT according to the thermal constants values. BT values are represented ranges from $9.4-43.7^{\circ} \mathrm{C}$, hence, the lower value in water and dense vegetation area then higher values in bare land and builtup area.

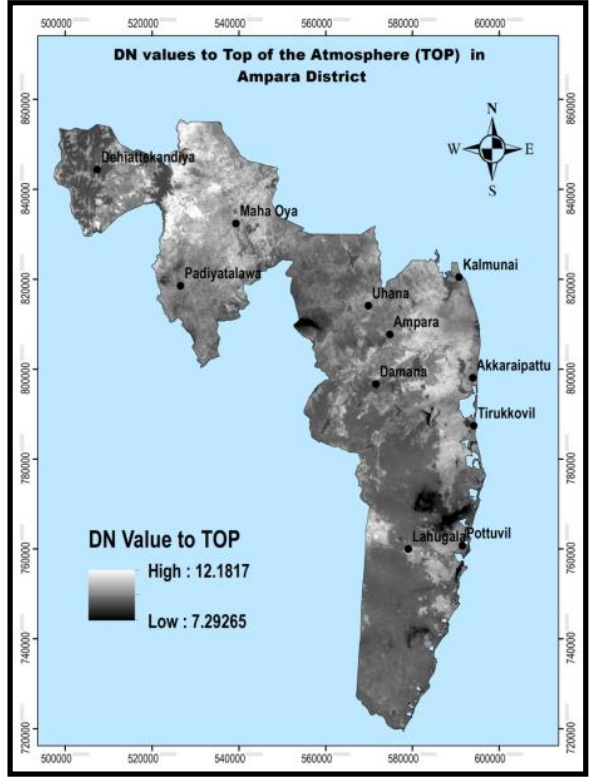

(a)

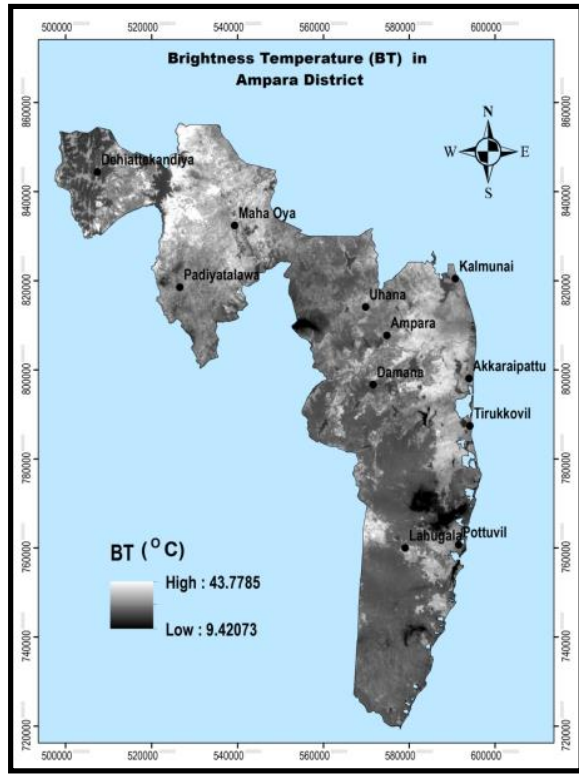

(b)

Fig. 5: (a) Range of DN value to TOA and Range of BT in Ampara District (Source: Computed by Author form Landsat 8 OLI/TIRS Data Level 2) 
LST: According to the analysis that to understand bare land and urban development impact on environment in the study area. This tool has proved as a dynamic tool to estimate LTS using BT information of TIRS sensor and LSE from PV cover of optical bands of OLI sensor of Landsat 8 satellite image.

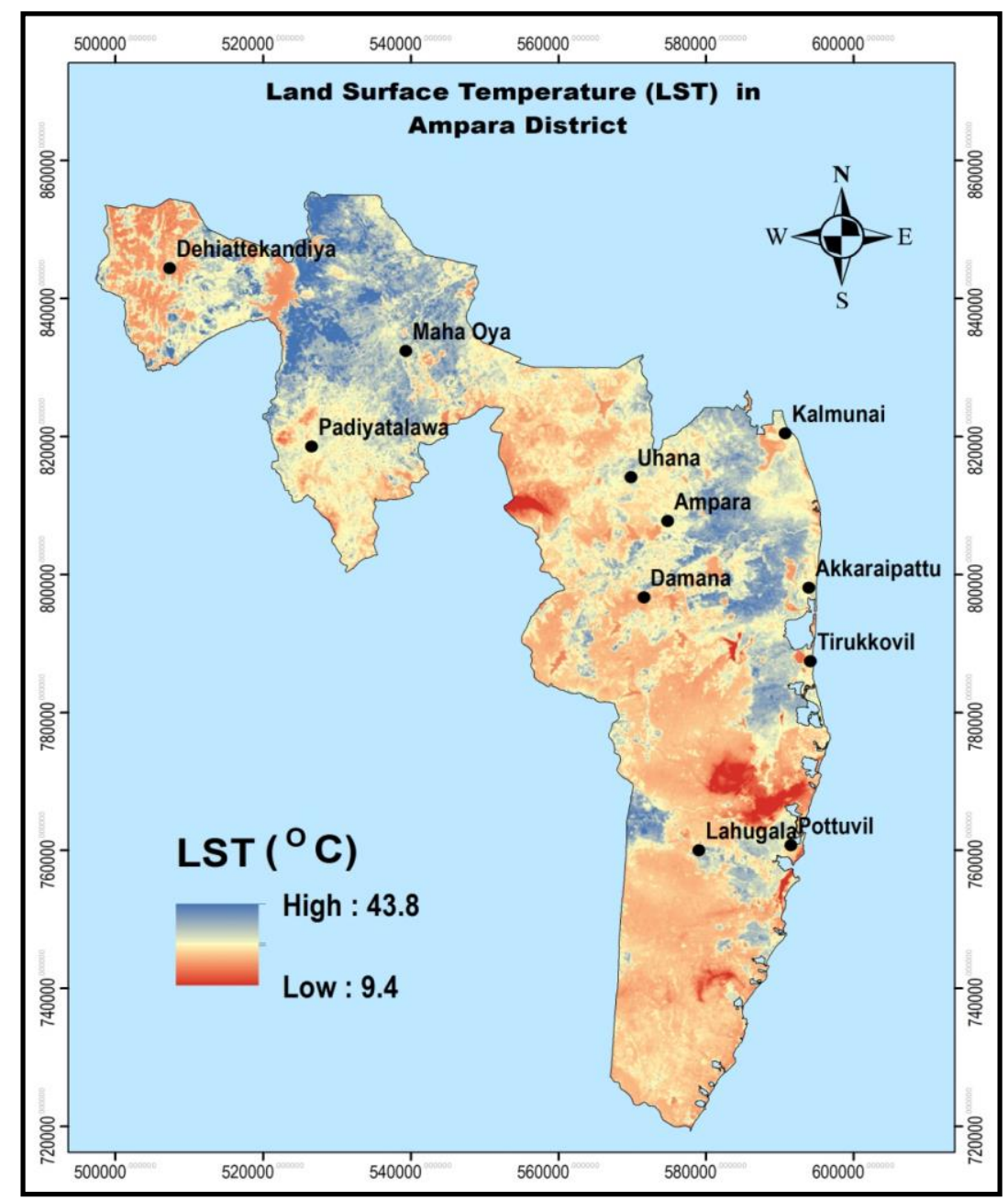

Fig. 6: Range of LST in Ampara District

(Source: Computed by Author form Landsat 8 OLI/TIRS Data Level 2)

TIRS data is major source for estimating surface emissivity for a region. It is effective to apply for surface emissivity estimation from fine spatial resolution satellite data such as Landsat 8 TIRS sensor. Thus, the NDVI value is estimated that minimum ranges which reflect that same materials are ideal that completely absorbs all incidence radiation and converts it as interval energy, then emits absorbed energy maximum possible rate per unit area.

In this connection, the LTS of Ampara District revealed a temperature range between $9.0^{\circ} \mathrm{C}-43$ ${ }^{0} \mathrm{C}$ in 2019 (see figure 6). The mean value of $30^{\circ} \mathrm{C}$ with standard deviation is 7.13. This implies that bare land and urban area dose bring up surface temperature by replacing natural vegetation surface such as bare land, metal, tar, building and concrete among others.

Hence, correlation analysis was performed between LST, Surface emissivity (SE) and NDVI values that SE and LST are more positive correlation within the parameter values. The coefficient determines $\mathrm{r}^{2}(0.994)$ but NDVI higher negative correlation with LST and EM that -0.998 and -0.990 respectively. It is more significant level as $\alpha$ value 0.01 (see table 4 ). 
Table 4: Correlations Coefficient

\begin{tabular}{|ll|l|l|l|}
\hline & & LTS & EM & NDVI \\
\hline LTS & Pearson Correlation & 1 & $.994^{* *}$ & $-.988^{* *}$ \\
& Sig. (2-tailed) & & .000 & .000 \\
& $\mathrm{~N}$ & 10 & 10 & 10 \\
\hline EM & Pearson Correlation & $.994^{* *}$ & 1 & $-.990^{* *}$ \\
& Sig. (2-tailed) & .000 & & .000 \\
& $\mathrm{~N}$ & 10 & 10 & 10 \\
\hline NDV & Pearson Correlation & $.988^{* *}$ & $-.990^{* *}$ & 1 \\
I & Sig. (2-tailed) & .000 & .000 & 10 \\
& $\mathrm{~N}$ & 10 & 10 & \\
\hline
\end{tabular}

**. Correlation is significant at the 0.01 level (2-tailed).

\section{Conclusions}

LST is a one of the key variable of Global climate changes which estimating radiating budget in heat balance as control of climate model. LST is major influenced factor by the ability of the surface emissivity. Thus, surface emissivity is vital role of estimating the radiance balance in the earth surface. The estimation of emissivity algorithm is based on an empirical relationship that determines by between spectral distinguish and minimum emissivity. It is used to equalize the number of unknown parameter and the number of measurement so that the set of Planck's equations for the thermal radiance can be inverted. LST is independent of wavelength which can be recovered from single band of radiance data that to provide the atmospheric characteristics by the emissivity.

In the study, Landsat 8 thermal imagery could be done the atmospheric correction by split window techniques. It will be provided more accurate retrieval of emissivity and surface temperature that was possible with previous Landsat sensor data. Thermal band could be provided a highresolution variation to precipitation indices for drought monitoring in the land surface. Landsat scale of evapotranspiration time-series is providing unique opportunity to investigate vegetation stress and drought vulnerability in edaphic condition.

Thus, LST was found to be higher rate in many places of Ampara district in Sri Lanka, it obvious to understand that low rainfall for experiences drought in many places by dry season in the district. Due to the higher rate of LST influence is deteriorating on agricultural practices in the district. Therefore, LST is strongly influenced by the availability of the surface emissivity that crucial for estimating the radiance balance at the LST.

\section{Future Scope}

In future studies, application of geo-informatics technique to assess LST can be differ by considering atmospheric effect and weather conditions of seasonal variations by processing the time series data. And also correlation between NDVI and LST can be revealed which helps specifically in extending UHI analysis. 
Acknowledgments: I wish to thank the Centre for Co-operation in Science and Technology among Developing Societies (CCSTDS) for providing institutional support and Many thanks are extended to the USGS for providing the Landsat 8 image of the case study area, free of charge.

Conflicts of Interest: The author declares no conflict of interest.

\section{References}

1. Anandababu, D.; Purushothaman, B. M.; Suresh Babu, S. "Estimation of Land Surface Temperature using LANDSAT 8 Data", International Journal of Advance Research, 2018, Ideas and Innovations in Technology, Volume 4, Issue 2.

2. Javed Mallick; Yogesh Kant; Bharath, B. D. “Estimation of Land Surface Temperature over Delhi Using Landsat-7 ETM+", J. Ind. Geophys. Union, 2008, Vol.12, No.3, pp.131-140.

3. Jeevalakshmi, D.; Narayana, S.; Reddy; Manikiam, B. “Land cover classification based on NDVI using LANDSAT8 time series: A case study Tirupati region", IEEE International Conference on Communication and Signal Processing (ICCSP), 2016, pp.1332-1335, doi:0.1109/ICCSP.2016.7754369.

4. Juan, C.; Jiménez-Muñoz José; Sobrino, A.; DraženSkokovi'c; Cristian Mattar; Jordi Cristóbal. "Land Surface Temperature Retrieval Methods from Landsat-8 Thermal Infrared Sensor Data", IEEE Geoscience and Remote Sensing Letters, 2014, Vol. 11, No. 10, pp. 1840- 1843.

5. Julia A. Barsi; John R. Schott; Simon J.; Hook; Nina G. Raqueno; Brian L. Markham; Robert G. Radocinski. "Landsat-8 Thermal Infrared Sensor (TIRS) Vicarious Radiometric Calibration", Remote Sensing, 2014, Vol.6, No. 11, pp. 11607- 11626.

6. Madurapperuma, B. D.; Dellysse, J. E.; Zahir, I. L. M.; Iyoob, A. L. "Mapping Shoreline Vulnerabilities Using Kite Aerial Photographs at Oluvil Harbor in Ampara", Proceedings of 7th International Symposium, 2017, SEUSL, 7th \& 8th December 2017.

7. Ren Zhibin; Zheng Haifeng; He Xingyuan; Zhang Dan; Yu Xingyang. "Estimation of the Relationship between Urban Vegetation Configuration and Land Surface Temperature with Remote Sensing", Journal of the Indian Society of Remote Sensing, 2015, 43(1):89-100, Doi 10.1007/s12524-014-0373-9.

8. Sellers, P. J.; Hall, F. G.; Asrar, G.; Strebel, D. E.; Murphy, R. E. "The first ISLSCP field experiment (FIFE)", Bull. Amer. Meteorol. Soc., 1988, vol. 69, pp. 22-27.

9. Ugur Avdan; Gordana Jovanovska. "Automated Mapping of Land Surface Temperature Using LANDSAT 8 Satellite Data”, Journal of Sensors, 2016, Vol. 2016, Article ID 1480307.

10. Wang, F.; Qin, Z.; Song, C.; Tu, L.; Karnieli, A.; Zhao, S. “An improved mono-window algorithm for land surface temperature retrieval from Landsat 8 thermal infrared sensor data," Remote Sensing, 2015, Vol. 7, no. 4, pp. $4268-4289$. 